\title{
Validation of the Portuguese version of the Community Assessment of Psychic Experiences and characterization of psychotic experiences in a Brazilian sample
}

\author{
Taciana C.C. Ragazzi, ${ }^{1}$ (iD Rosana Shuhama, ${ }^{1,2}$ iD Jorge Sinval, ${ }^{3,4,5}$ (iD João Marôco, ${ }^{4}$ (iD \\ Fabiana Corsi-Zuelli, ${ }^{1}$ iD Daiane L. da Roza, ${ }^{1}$ iD Jim van Os, ${ }^{6,7,8}$ iD Paulo R. Menezes, ${ }^{2,9}$ iD \\ Cristina M. Del-Ben ${ }^{1,2}$ iD
}

\begin{abstract}
${ }^{1}$ Departamento de Neurociências e Ciências do Comportamento, Faculdade de Medicina de Ribeirão Preto, Universidade de São Paulo (FMRP-USP), Ribeirão Preto, SP, Brazil. ${ }^{2}$ Núcleo de Pesquisa em Saúde Mental Populacional, Universidade de São Paulo (USP), São Paulo, $S P$, Brazil. ${ }^{3}$ Business Research Unit (BRU-IUL), Instituto Universitário de Lisboa (ISCTE-IUL), Lisbon, Portugal. ${ }^{4}$ William James Center for Research, ISPA, Instituto Universitário, Lisbon, Portugal. ${ }^{5}$ Faculdade de Medicina, Universidade de Lisboa, Lisbon, Portugal. ${ }^{6}$ Department of Psychiatry, Utrecht University Medical Center, Utrecht, The Netherlands. ${ }^{7}$ Department of Psychiatry and Psychology, School for Mental Health and Neuroscience (MHeNS), Maastricht University Medical Centre, Maastricht, The Netherlands. ${ }^{8}$ King's Health Partners Department of Psychosis Studies, Institute of Psychiatry, King's College London, London, United Kingdom. ${ }^{9}$ Departamento de Medicina Preventiva, Faculdade de Medicina, USP, São Paulo, SP, Brazil.
\end{abstract}

\begin{abstract}
Objective: We investigated: i) the reliability and validity of a Brazilian version of the Community Assessment of Psychic Experiences (CAPE), developed to detect and characterize psychotic experiences in the general population; and ii) the association between psychotic experiences, childhood adversity, and cannabis use in a population-based sample.

Methods: We performed factorial analyses and generalized linear models with CAPE scores as the dependent variable in a sample composed of 217 first-episode psychosis patients, 104 unaffected biological siblings, and 319 non-psychotic population-based participants.

Results: After removing seven items from its positive dimension and two items from its negative dimension, a 33-item Brazilian version of the CAPE showed acceptable adjustment indices (confirmatory fit index $=0.895$; goodness of fit index $=0.822$; parsimony goodness of fit index = 0.761 ; root mean square error of approximation $[R M S E A]=0.055, p[R M S E A \leqslant 0.05]=0.04$ ) and internal consistency in all its dimensions ( $>0.70$ ). Childhood adversity was associated with higher scores in all three dimensions, as well as with total score. Lifetime cannabis use was associated with higher scores only in the positive dimension.

Conclusion: The proposed Brazilian version of the CAPE corroborates the tridimensional approach for assessing psychosis-proneness, and the frequency and severity of psychotic manifestations are distributed as a spectrum in the general population.
\end{abstract}

Keywords: Psychotic experience; psychometric property; general population, cannabis; childhood adversity

\section{Introduction}

Psychotic disorders affect around $3 \%$ of the world's population and are an important public health problem due to their high morbidity and mortality. ${ }^{1}$ Epidemiological studies indicate that psychotic symptoms are not only experienced by people diagnosed with psychotic disorders, but also by healthy individuals in the general population. ${ }^{2-4}$ These so-called psychotic experiences (PEs) are considered part of a spectrum in which psychotic symptoms are dimensionally distributed throughout

Correspondence: Daiane L. da Roza, Divisão de Psiquiatria, Departamento de Neurociências e Ciências do Comportamento, Faculdade de Medicina de Ribeirão Preto, Universidade de São Paulo, Avenida Bandeirantes, 3900, CEP 14049-900, Ribeirão Preto, SP, Brazil.

E-mail: daianeroza@ hotmail.com

Submitted Jul 30 2019, accepted Nov 05 2019, Epub Feb 212020. the general population. ${ }^{4,5}$ According to this model, the more intense these experiences are, the greater the functional impairment, and the closer individuals come to clinical diagnosis. ${ }^{5}$ In addition, known risk factors for psychotic disorders, such as cannabis use ${ }^{6}$ and childhood adversity, ${ }^{7}$ are also associated with PEs.

The annual prevalence of PEs is estimated at $7.2 \%$ in the general population, ${ }^{5}$ although this varies across countries and age-groups, ranging from $19 \%$ in the United Kingdom ${ }^{8}$ and $17.5 \%$ in The Netherlands ${ }^{9}$ to $11.7 \%$ in Australia. ${ }^{10}$ Epidemiological data also suggest a

How to cite this article: Ragazzi TCC, Shuhama R, Sinval J, Marôco J, Corsi-Zuelli F, Roza DL, et al. Validation of the Portuguese version of the Community Assessment of Psychic Experiences and characterization of psychotic experiences in a Brazilian sample. Braz J Psychiatry. 2020;42:389-397. http://dx.doi.org/10.1590/1516-44462019-0611 
correlation between PE prevalence and the rate of psychosis. ${ }^{11}$ In low- and middle-income countries, little is known about manifestations on the psychosis spectrum. In a study conducted in the city of São Paulo, Brazil, PEs were described in $30.7 \%$ of the sample, although they had no overall impact on everyday life. ${ }^{2}$

The striking variation in PE prevalence around the globe might be explained by the different tools used to survey PEs and, consequently, the distinctive criterion used to estimate their occurrence. For instance, the use of instruments originally developed to diagnose established psychiatric disorders could mischaracterize the occurrence of PEs, resulting in either under- or overestimation. A similar situation could occur when PEs are evaluated through self-report instruments without the supervision of a mental health specialist to ensure data quality. Moreover, PEs could also be influenced by a combination of specific social and biological factors, which could vary around the world. Thus, the worldwide occurrence of PEs should be studied using a homogeneous methodology, including specially developed instruments, especially in low- and middle-income countries, where such validation is lacking.

The Community Assessment of Psychic Experiences (CAPE) scale was specifically developed to study the psychosis spectrum in epidemiological studies. The CAPE evaluates the occurrence of PEs and the distress caused by such experiences in the general population according to three dimensions - positive, negative, and depressive constructs based on the symptom clusters observed in psychotic patients. ${ }^{3}$

The CAPE has been validated in several European countries, ${ }^{3,12-15}$ with good psychometric properties. ${ }^{16}$ However, this instrument has not yet been validated in low- and middle-income countries, which might partly explain the lack of studies on PEs in these populations. The adaptation of the CAPE to different languages and cultures could contribute to a better understanding of epidemiological variance in the psychosis spectrum in distinct geographic areas and ethnic groups, allowing better cross-country comparison of data obtained through a homogenous construct and similar methodological procedures.

Therefore, the aim of this study was to investigate the reliability and validity of the Portuguese version of the CAPE in a Brazilian sample that consisted of first-episode psychosis (FEP) patients, their unaffected siblings, and non-psychotic population-based participants. To contribute to construct validity, we investigated whether sociodemographic characteristics, history of childhood adversity, and cannabis use were associated with PE occurrence among the population-based participants in the expected direction. ${ }^{5}$

\section{Methods}

This study is part of an epidemiologic investigation called Schizophrenia and Other Psychoses Translational Research: Environment and Molecular Biology (STREAM). It aimed to estimate the incidence of schizophrenia and other psychoses and investigate possible associations between environmental and biological factors in the occurrence of mental disorders in Ribeirão Preto, state of São Paulo, Brazil. ${ }^{17,18}$ The epidemiologic catchment area consists of Ribeirão Preto, the main city, and other 25 municipalities, with a total population of $1,327,989$ inhabitants (Brazilian Census, $2010^{19}$ ).

The STREAM study is part of the multicenter European Network of National Schizophrenia Networks Studying Gene - Environment Interactions (EU-GEI) study (http:// www.eu-gei.com), an international consortium to investigate the etiology, mechanisms and prognoses of schizophrenia and other psychotic disorders. ${ }^{18,20}$

\section{Participants}

A total of 640 participants were recruited, consisting of 217 FEP patients, 104 unaffected siblings of the FEP patients, and 319 population-based non-psychotic individuals. All participants were aged between 16-64 years old and resided in the Ribeirão Preto epidemiologic catchment area. The study was conducted between April 2012 and March 2015.

Eligible FEP patients had made first contact with a mental health service due to the manifestation of psychotic symptoms during the 3-year period of the STREAM study. Patients whose psychotic symptoms were due psychoactive substance use or another medical condition were excluded. The inclusion of siblings was based on the patient's verbal consent to their invitation and no history of psychosis. We included the biological siblings in our study because these are considered a high risk group for psychosis, given the shared genetic and environmental factors. The population-based participants consisted of a representative sample of the at-risk population in the epidemiologic catchment area who had never presented psychotic symptoms.

Clinical assessment was conducted by trained psychologists and psychiatric nurses using the Structured Clinical Interview (SCID) ${ }^{21}$ for DSM-IV for the confirmation (patients) or the exclusion (siblings and population-based participants) of a psychotic disorder diagnosis.

\section{Instruments}

The CAPE consists of 42 items intended to measure PEs, which are estimated in three dimensions: positive (20 items), negative (14 items), and depressive (eight items). The instrument is structured in four-point Likert scales to register the frequency with which PEs occur ( $1=$ never, $4=$ almost always) and the degree of suffering they have caused $(1=\text { none, } 4=\text { much })^{3}$

The reliability and factorial validity of the CAPE have been estimated across multiple samples. ${ }^{16,22}$ In a metaanalytic review, Mark \& Toulopoulou ${ }^{16}$ found a mean reliability estimate of 0.91 (standard deviation [SD] = 0.05). The CAPE-42's three factorial structure has also been confirmed through confirmatory factorial analysis (CFA) and exploratory factorial analysis (EFA). ${ }^{12,14}$ Recently, its factorial equivalence was also corroborated in an EU-GEI study, in which the STREAM data, reported herein, were included (confirmatory fit index [CFI] 
and Tucker Lewis index $>0.9$; root mean square error of approximation [RMSEA] $<0.05) .^{22}$

The process of translating and adapting the CAPE to Brazilian Portuguese was undertaken by the STREAM research team. Two medical doctors, specialists in mental health, performed independent translations and the final consensus version included the participation of a third specialist in the area. This version underwent backtranslation by a bilingual researcher associated with the EU-GEI consortium.

The Childhood Trauma Questionnaire is a self-report questionnaire investigating five subtypes of childhood adversity (emotional, physical and sexual abuse, and physical and emotional neglect). The instrument consists of 25 items, which are rated on a five-point Likert scale ( $1=$ never true, $5=$ very often true) ranging from five to 25 points. ${ }^{23,24}$

The Cannabis Experience Questionnaire consists of 16 questions that explore the respondent's usage pattern of cannabis and other psychoactive substances, including information about date of onset, frequency, expenditures, and symptoms related to drug consumption. ${ }^{25}$ Only information about cannabis use was considered in this study. The frequency of cannabis use was classified in three main categories: a) mild/moderate: when the reported frequency was "only once or twice in my life," "a few times a year," or "a few times a month"; b) heavy: when the frequency reported was "more than once a week" or "everyday"; and c) never used.

\section{Data collection}

The test battery was applied to the sample according to EU-GEI consortium guidelines. To standardize the data collection and minimize the influence of low education level, all items were read to the participants.

\section{Statistical analysis}

\section{Demographic and clinical characterization}

IBM SPSS version 20 was used to analyze the demographic and clinical characterization of the sample. Data were explored through mean (M), SD, median, and frequencies. Pearson's chi-square test was used to evaluate categorical variables. The Lilliefors-corrected KolmogorovSmirnov test was used to examine the normal distribution of the sample. Ordinal variables were analyzed using oneway analysis of variance with a Bonferroni post-hoc test. For comparisons between two groups, we used Student's $t$-test. P-values $\leqslant 0.05$ were considered significant.

\section{Psychometric evidence}

Initially, we evaluated the normality distribution of the items by asymmetry (Sk), Kurtosis (Ku), and frequency (\%), with values considered as non-indicative of severe normality violation when items presented $\mathrm{Sk} \leqslant 3.0$ and $\mathrm{Ku}<10.0$. $^{26}$

CFA was conducted to determine whether the construct presented an adequate fit for this study's sample.
We used as goodness of fit indices (GFI), chi-square and degrees of freedom ratio (chi-square/df), CFI, parsimony GFI (PGFI), and RMSEA. Acceptable goodness of fit was found for the model (CFI and GFI > 0.90, PGFI values > 0.60 , and RMSEA values $<0.10) .{ }^{26,27}$ EFA revealed an acceptable factor load ( $>0.50$ ). The CFA and EFA analyses were performed in AMOS $^{\circledR}$ version 23.0.

The internal consistency was calculated with the standardized Cronbach's alpha coefficient $(\alpha)$ for each factor suggested in the inventories and the stratified alpha coefficient for the total scale. We considered $\geqslant 0.70$ an acceptable value. ${ }^{26}$

\section{Regression analysis}

We used a generalized linear model to evaluate the association between the dependent variable (CAPE scores) and the independent variables (childhood adversity and cannabis use). In the first step (model 1), we investigated the main effects of childhood adversity (divided into three categories: no maltreatment (reference), one childhood adversity, and two or more childhood adversities) and cannabis use (also divided into three categories: never used [reference], mild/moderate use, and heavy use) on PE outcomes (model 1, unadjusted). As a second step, we performed the same analysis, while adjusting for a priori confounders, i.e., sex, age, marital status, and years of education (model 2). Statistical analysis was based on $\beta$ and standard error (SE). SAS ${ }^{\circledR}$ version 9.4 statistical package was used for this analysis.

\section{Ethics statement}

All participants gave written informed consent prior to inclusion, and the study was approved by the local ethics committee (process 12606/2012).

\section{Results}

\section{Features of the sample}

No significant age differences were found among the three groups (Table 1). The percentage of males was higher in the patients and population-based groups than the unaffected siblings. A higher percentage of patients classified as having less education (i.e., $\leqslant 9$ years) than the other groups, and the majority of the patients were not in a stable relationship, unlike the unaffected siblings and population-based participants (Table 1).

As expected, the patient group scored significantly higher across the three PE dimensions and higher for distress on the Brazilian CAPE-33 (see below) than the other groups. No statistically significant differences were found between unaffected siblings and population-based participants (Table 1).

\section{CAPE psychometric evidence}

We analyzed the CAPE's psychometric evidence for the total sample $(n=640)$. Items 34,41 , and 42 had the lowest 


\begin{tabular}{|c|c|c|c|c|c|}
\hline CAPE-33 & $\begin{array}{l}\text { First-episode psychosis } \\
\text { patients }(n=217)\end{array}$ & $\begin{array}{l}\text { Siblings } \\
(\mathrm{n}=104)\end{array}$ & $\begin{array}{l}\text { Population-based } \\
\text { participants }(n=319)\end{array}$ & Statistic test & $p$-value \\
\hline Age in years & $30.7(12.0)$ & $30.9(11.1)$ & $33.0(12.5)$ & $2.7^{*}$ & 0.07 \\
\hline Male, n (\%) & $128(59.0)$ & $29(27.9)$ & $153(48.0)$ & $42.81^{\dagger}$ & $<0.01$ \\
\hline Education $\leqslant 9$ years, $\mathrm{n}(\%)$ & $119(54.8)$ & $35(33.7)$ & $78(24.5)$ & $51.97^{\dagger}$ & $<0.01$ \\
\hline Single, $n(\%)$ & $158(72.8)$ & $48(46.2)$ & $145(45.5)$ & $27.29^{\dagger}$ & $<0.01$ \\
\hline \multicolumn{6}{|l|}{ Occurrence of PEs } \\
\hline Positive & $22.8(7.9)$ & $15.6(3.7)$ & $15.4(2.7)$ & $144.58 *$ & $<0.01$ \\
\hline Negative & $23.5(8.0)$ & $18.0(6.5)$ & $17.4(4.7)$ & 64.86* & $<0.01$ \\
\hline Depressive & $16.8(5.9)$ & $13.7(4.8)$ & $13.3(4.0)$ & $36.35^{*}$ & $<0.01$ \\
\hline Total & $63.1(19.0)$ & $47.3(14.1)$ & $46.0(10.0)$ & $98.45^{*}$ & $<0.01$ \\
\hline \multicolumn{6}{|l|}{ Distress caused by PEs } \\
\hline Positive & $17.3(11.5)$ & $7.7(7.2)$ & $5.6(4.4)$ & $102.24 *$ & $<0.01$ \\
\hline Negative & $23.5(8.0)$ & $18.0(6.5)$ & $17.4(4.7)$ & $52.20 *$ & $<0.01$ \\
\hline Depressive & $16.1(8.4)$ & $13.2(7.7)$ & $11.2(7.1)$ & $28.89 *$ & $<0.01$ \\
\hline Total & $53.2(28.2)$ & $34.2(22.3)$ & $28.9(17.9)$ & $90.45^{*}$ & $<0.01$ \\
\hline
\end{tabular}

Data presented as mean (standard deviation), unless otherwise specified.

CAPE = Community Assessment of Psychic Experiences; PEs = psychotic experiences.

* One-way analysis of variance.

†Pearson's chi-square test.

means, most commonly scored as never. These items also did not obtain sufficient $\mathrm{Sk}$ and $\mathrm{Ku}$ scores and violated the normality criterion (Table 2).

The original three-factor model of the CAPE-42 adjusted for the total sample underwent CFA analysis and presented a poor/acceptable fit quality in our sample. Consequently, the original model of the instrument was refined through EFA. In this phase, nine items that did not obtain a factorial load $>0.50$ were eliminated. Among these items, seven were related to the positive dimension: 5 Messages from TV, 6 False appearance, 11 Being important, 13 Being special, 17 Influenced by devices, 20 Voodoo, and 41 Capgras syndrome; and two were related to the negative dimension: 4 Not talkative and 8 No emotion.

After removing these nine items, a new three-dimensional model, now with 33 items (CAPE-33), presented improved CFA results, including an acceptable/good adjustment in the following adjustment indexes: CFI = 0.895; $\mathrm{GFI}=0.822 ; \mathrm{PGFI}=0.761 ; \mathrm{RMSEA}=0.055$, $\mathrm{p}$ [RMSEA $\leqslant 0.05]=0.04$.

The three dimensions of the resulting CAPE-33 obtained very good internal consistency indexes: positive $(\alpha=0.88)$, negative $(\alpha=0.89)$, and depressive $(\alpha=0.86)$. The CAPE-33 scale, as a whole, presented an $\alpha=0.94$.

\section{Psychotic experiences in population-based participants}

Women had significantly higher scores overall, especially the negative and depressive dimensions of the Brazilian CAPE-33. No statistically significant differences were found regarding age, marital status or education among the participants ( $p$-values $\geqslant 0.28$ ) (Table 3 ).

Seventy $(21.9 \%)$ of the 319 population-based participants reported experiencing childhood adversity (45 women and 25 men). Among them, 38 reported one type of adversity and 32 reported two or more types according to the Childhood Trauma Questionnaire. Fifty-nine (18.5\%) participants had a positive lifetime history of cannabis use; $30(9.4 \%)$ of them reported light/moderate use and $29(9.1 \%)$, heavy use.

Having experienced two or more childhood adversities was associated with greater reports of PEs in all the three dimensions, as well as with higher total CAPE scores, than having experienced one type of or no childhood adversity. In addition, having experienced only one adversity in childhood was also associated with higher negative, depressive, and total CAPE scores (Table 4).

Compared to those who never used cannabis, only heavy cannabis use was associated with higher PE scores in the positive dimension and, when adjusted for sociodemographic variables, in total CAPE scores (Table 4).

\section{Discussion}

We investigated the psychometric properties of the Portuguese version of the CAPE-42 and the association between childhood adversity, cannabis use and the occurrence of PEs in Brazilian individuals from the general population. The Brazilian version of the CAPE presented acceptable reliability and validity after removing nine items, maintaining the factorial distribution proposed in the original instrument ${ }^{3}$ for all the three dimensions: positive, negative, and depressive. PEs were detected in individuals from the Brazilian community and were significantly associated with heavy cannabis use and childhood adversity.

Although the total sample size $(n=640)$ met the requirements for CFA, ${ }^{26}$ good adjustment indexes were not initially obtained the original CAPE model. An EFA was then performed ${ }^{26}$ and nine items did not obtain a good factorial load ( $>0.50$ ), seven (items $5,6,11,13,17$, and 20) from the positive dimension and two (items 4 and 8 ) from the negative dimension.

One possible explanation for the low scores on these items is that terms used for the Capgras syndrome and Voodoo items, for example, might have been unfamiliar to 
Table 2 Descriptive statistics, factors loads of the confirmatory factor analysis and internal consistency of CAPE-42 items in a Brazilian sample $(n=640)$

\begin{tabular}{|c|c|c|c|c|c|c|c|c|c|}
\hline \multirow[b]{2}{*}{ Items CAPE-42 } & \multirow[b]{2}{*}{$\begin{array}{l}\text { Mean } \\
\text { (SD) }\end{array}$} & \multicolumn{4}{|c|}{ Frequency (\%) } & \multirow[b]{2}{*}{ Sk } & \multirow[b]{2}{*}{$\mathrm{Ku}$} & \multirow[b]{2}{*}{$\begin{array}{l}\text { Factors } \\
\text { loads }\end{array}$} & \multirow[b]{2}{*}{$\begin{array}{c}\text { Internal } \\
\text { consistency }\end{array}$} \\
\hline & & Never & Sometimes & Frequently & $\begin{array}{c}\text { Almost } \\
\text { often }\end{array}$ & & & & \\
\hline 1. Sad & $2.42(0.86)$ & 6 & 65 & 10 & 19 & 0.86 & -0.34 & 0.69 & 0.64 \\
\hline 2. Double meaning & $1.68(0.85)$ & 50 & 38 & 5 & 7 & 1.31 & 1.24 & 0.53 & 0.53 \\
\hline 3. Lack of enthusiasm & $1.88(0.98)$ & 42 & 40 & 6 & 12 & 1.03 & 0.095 & 0.60 & 0.55 \\
\hline 4. Not talkative & $1.91(1.06)$ & 46 & 32 & 7 & 15 & 0.94 & -0.39 & $<0.50$ & \\
\hline 5. Messages from TV & $1.39(0.66)$ & 68 & 27 & 2 & 3 & 2.03 & 4.66 & $<0.50$ & \\
\hline 6. False appearance & $2.18(0.84)$ & 17 & 59 & 13 & 11 & 0.77 & 0.22 & $<0.50$ & \\
\hline 7. Persecuted & $1.49(0.83)$ & 67 & 22 & 5 & 6 & 1.80 & 2.5 & 0.60 & 0.61 \\
\hline 8. No emotion & $1.51(0.78)$ & 62 & 30 & 3 & 5 & 1.77 & 2.86 & $<0.50$ & \\
\hline 9. Pessimism & $1.73(0.90)$ & 50 & 35 & 7 & 8 & 1.22 & 0.73 & 0.57 & 0.51 \\
\hline 10. Conspiracy & $1.41(0.78)$ & 72 & 20 & 3 & 5 & 2.09 & 3.82 & 0.56 & 0.55 \\
\hline 11. Be important & $1.59(0.90)$ & 62 & 25 & 5 & 8 & 1.56 & 1.49 & $<0.50$ & \\
\hline 12. No future & $1.58(0.89)$ & 62 & 26 & 4 & 8 & 1.58 & 1.63 & 0.63 & 0.57 \\
\hline 13. Be special & $1.44(0.85)$ & 73 & 17 & 3 & 7 & 2.01 & 3.07 & $<0.50$ & \\
\hline 14. Not worth living & $1.64(0.92)$ & 57 & 29 & 5 & 9 & 1.44 & 1.15 & 0.75 & 0.69 \\
\hline 15. Telepathy & $1.31(0.68)$ & 79 & 15 & 3 & 3 & 2.55 & 6.34 & 0.55 & 0.54 \\
\hline 16. No interest in others & $1.74(0.87)$ & 47 & 40 & 5 & 8 & 1.22 & 0.94 & 0.61 & 0.61 \\
\hline 17. Influenced by devices & $1.32(0.74)$ & 81 & 11 & 3 & 5 & 2.54 & 5.69 & $<0.50$ & \\
\hline 18. Lack of the motivation & $1.81(0.87)$ & 41 & 45 & 6 & 8 & 1.13 & 0.78 & 0.70 & 0.69 \\
\hline 19. Frequently cry & $1.64(0.94)$ & 60 & 24 & 7 & 9 & 1.39 & 0.82 & 0.64 & 0.58 \\
\hline 20. Vodoo & $1.56(0.92)$ & 65 & 22 & 4 & 9 & 1.67 & 1.74 & $<0.50$ & \\
\hline 21. No energy & $1.77(0.87)$ & 44 & 42 & 6 & 8 & 1.18 & 0.86 & 0.68 & 0.65 \\
\hline 22. Odd looks & $1.63(0.89)$ & 58 & 29 & 6 & 7 & 1.44 & 1.24 & 0.56 & 0.55 \\
\hline 23. Empty mind & $1.52(0.85)$ & 65 & 24 & 5 & 6 & 1.71 & 2.16 & 0.64 & 0.57 \\
\hline 24. Thought withdrawal & $1.23(0.66)$ & 86 & 8 & 2 & 4 & 3.00 & 9.24 & 0.58 & 0.6 \\
\hline 25. Lack of activity & $1.65(0.91)$ & 57 & 29 & 6 & 8 & 1.39 & 1.01 & 0.63 & 0.56 \\
\hline 26. Thought insertion & $1.28(0.67)$ & 81 & 13 & 3 & 3 & 2.67 & 6.9 & 0.65 & 0.59 \\
\hline 27. Blunted feelings & $1.36(0.72)$ & 75 & 18 & 3 & 4 & 2.28 & 4.9 & 0.62 & 0.59 \\
\hline 28. Thought broadcasting & $1.35(0.72)$ & 76 & 17 & 3 & 4 & 2.28 & 4.84 & 0.60 & 0.58 \\
\hline 29. Lack of spontaneity & $1.48(0.76)$ & 64 & 28 & 3 & 5 & 1.78 & 2.92 & 0.57 & 0.54 \\
\hline 30. Thought echo & $1.32(0.70)$ & 78 & 16 & 2 & 4 & 2.52 & 6.13 & 0.62 & 0.55 \\
\hline 31. External control & $1.31(0.71)$ & 80 & 13 & 3 & 4 & 2.57 & 6.13 & 0.66 & 0.6 \\
\hline 32. Blunted emotions & $1.69(0.92)$ & 54 & 32 & 5 & 9 & 1.33 & 0.89 & 0.68 & 0.61 \\
\hline 33. Verbal hallucinations & $1.48(0.83)$ & 68 & 22 & 4 & 6 & 1.85 & 2.65 & 0.71 & 0.67 \\
\hline 34. Voices conversing & $1.23(0.65)$ & 87 & 8 & 2 & 3 & 3.19 & 9.67 & 0.55 & 0.55 \\
\hline 35. Lack of hygiene & $1.42(0.77)$ & 71 & 20 & 4 & 5 & 2.03 & 3.61 & 0.57 & 0.53 \\
\hline 36. Unable to terminate & $1.66(0.85)$ & 52 & 36 & 5 & 7 & 1.38 & 1.42 & 0.65 & 0.6 \\
\hline 37. Lack of hobby & $1.58(0.85)$ & 60 & 29 & 4 & 7 & 1.57 & 1.81 & 0.58 & 0.56 \\
\hline 38. Guilty & $1.77(0.85)$ & 44 & 42 & 7 & 7 & 1.12 & 0.81 & 0.57 & 0.5 \\
\hline 39. Failure & $1.62(0.90)$ & 59 & 28 & 5 & 8 & 1.5 & 1.35 & 0.75 & 0.69 \\
\hline 40. Feeling tense & $2.15(0.94)$ & 24 & 51 & 11 & 14 & 0.71 & -0.27 & 0.66 & 0.6 \\
\hline 41. Capgras syndrome & $1.11(0.42)$ & 93 & 6 & 0 & 1 & 5.20 & 30.03 & $<0.50$ & \\
\hline 42. Visual hallucinations & $1.24(0.63)$ & 84 & 11 & 2 & 3 & 3.08 & 9.55 & 0.61 & 0.55 \\
\hline
\end{tabular}

CAPE = Community Assessment of Psychic Experiences; Ku = kurtosis; SD = standard deviation; Sk = asymmetry.

the participants, which could have led to confusion about their meaning. Thus, a high frequency of never responses occurred for these items. According to the Index of Basic Education Development, ${ }^{28}$ Brazilian education levels are still below expectations for emerging countries. An alternative hypothesis is that these items describe ideas and behaviors that are culturally misjudged by the sample, particularly those related to religious or mystical content, which may also have led to inconsistencies in the responses. Despite Brazil's cultural diversity and religious syncretism, Christianity is the largest religion, with a high number of Catholics (64.6\%) and Protestants (22.2\%) citizens (http://www.ibge.gov.br).

Item 6 (False appearance) may have suggested a double meaning and thus failed to explain the construct it was intended to represent. In the Spanish version of the CAPE, the same item did not obtain a good factorial load and was reallocated to the depressive dimension. ${ }^{14}$ The same misinterpretation could have occurred in items 4 (Not talkative) and 8 (No emotion). In the German version of the CAPE, for example, items 4 and 8 were made subfactors in the negative dimension (emotional withdrawal and affective blunting, respectively), which allowed better factor loads and good adjustment indices. ${ }^{15}$

After the nine items were removed, acceptable adjustment indices were found in CFA of the Brazilian CAPE-33, which were distributed in three dimensions: 13 positive, 12 negative, and eight depressive. The absolute (CFI = $0.895)$ and relative $(\mathrm{GFI}=0.822)$ indices were very close to good quality $(>0.9)$. In parsimony analysis, the instrument obtained a PGFI $=0.761$ and, in the population discrepancy, the adjustment was acceptable (RMSEA = $0.055)$, being close to the reference value $(\leqslant 0.05){ }^{26}$

The internal consistency analysis of the CAPE-33 resulted in good Cronbach's $\alpha$ values in the three dimensions. The negative dimension obtained the highest value 
$(\alpha=0.89)$, close to that found in a Spanish study, ${ }^{14}$ in which psychotic patients were assessed $(\alpha=0.88)$, as well as that found in an Italian study, ${ }^{13}$ which included a sample of non-psychotic students $(\alpha=0.86)$. The German version of the CAPE found the same internal consistency value in the positive dimension as the Brazilian CAPE-33 $(\alpha=0.88)$ and a very close value in the depressive dimension $(\alpha=0.85$ for the German version and $\alpha=0.86$ for the Brazilian version). ${ }^{15}$ This agreement could be due to the characteristics of the samples, since both studies included people from the general population and psychosis patients.

The distribution of the FEP sample by sex was similar to that described in epidemiological studies, ${ }^{18}$ with a higher percentage of PEs observed in men. The severity of the disorder was associated with lower educational levels and poor social functioning. ${ }^{29}$

As expected, the patient group reported PEs at a greater frequency than the unaffected siblings group and the population-based group. Although we cannot rule out the possibility of under-reporting by the siblings, we do not believe that this occurred, first of all because the included siblings were possibly healthier, and perhaps the women were caregivers. In addition, in all dimensions, there were siblings and population-based participants with high CAPE-33 scores, similar to those observed in the patient group. These participants, who varied from expected group values, are called outliers in statistical terms, meaning atypical values that are far from standard values for a given sample. The presence of atypical values in CAPE-33 scores among individuals undiagnosed with a psychotic disorder corroborates the hypothesis of $\mathrm{PE}$ continuity in the general population, reinforcing the proposition that psychosis is not limited to categories described in diagnostic manuals, such as the DSM-5.

Reports of PEs in the negative and depressive dimensions were greater among women than men. This could be associated with a higher prevalence of depressive symptoms in women and, thus, a predisposition to report negative and depressive experiences. ${ }^{30}$ In an Italian study, ${ }^{13}$ for example, although the authors indicated that no substantial differences were found between the sexes, mean CAPE scores were higher in all dimensions for women than men.

We found no association between PE and age range, marital status, or education level. This result seems to go against previous data suggesting that PEs would be more common in younger, less educated, and single people. ${ }^{5,31}$ This could indicate that PEs are characterized differently in emerging countries than in countries with higher incomes, where such studies have predominated. ${ }^{32}$

In our Brazilian community-based sample, the experience of any childhood adversity (physical, emotional, or sexual abuse, or physical or emotional neglect) was positively associated with PEs in all CAPE-33 dimensions. This agrees with what has been reported in previous studies on non-clinical populations. ${ }^{33,34}$ Another important finding was the association of two or more types of childhood adversity with greater reports of PEs in all CAPE-33 dimensions. This result could be related to the association between higher frequency, 
Table 4 Generalized linear models of the occurrence of psychotic experiences as measured by the Brazilian CAPE-33, according to childhood trauma and cannabis use in population-based participants $(n=319)$

\begin{tabular}{|c|c|c|c|c|c|c|c|}
\hline \multirow[b]{2}{*}{ CAPE-33 } & \multirow[b]{2}{*}{$\mathrm{n}$} & \multirow[b]{2}{*}{ Mean (SD) } & \multirow[b]{2}{*}{ Min-Max } & \multicolumn{2}{|c|}{ Crude } & \multicolumn{2}{|c|}{ Adjusted* } \\
\hline & & & & $\beta$ (SE) & $p$-value & $\beta$ (SE) & $p$-value \\
\hline \multicolumn{8}{|l|}{ Positive dimension (13-30) } \\
\hline Intercept & & & & $15.00(0.16)$ & $<0.01$ & $14.76(0.89)$ & $<0.01$ \\
\hline No adversity & 249 & $15.0(2.3)$ & $13-24$ & Reference & & Reference & \\
\hline One early adversity & 38 & $15.8(3.1)$ & $13-23$ & $0.80(0.46)$ & 0.08 & $0.76(0.46)$ & 0.10 \\
\hline$\geqslant 2$ early adversities & 32 & $17.7(4.2)$ & $13-30$ & $2.68(0.49)$ & $<0.01$ & $2.62(0.51)$ & $<0.01$ \\
\hline Intercept & & & & $15.16(0.16)$ & $<0.01$ & $15.41(0.91)$ & $<0.01$ \\
\hline No cannabis use & 260 & $15.1(2.6)$ & $13-30$ & Reference & & Reference & \\
\hline Use $\mathrm{mild} /$ moderate & 30 & $15.6(3.3)$ & $13-25$ & $0.46(0.52)$ & 0.37 & $0.54(0.52)$ & 0.30 \\
\hline Heavy user & 29 & $17.0(3.0)$ & $13-22$ & $1.80(0.53)$ & $<0.01$ & $1.87(0.54)$ & $<0.01$ \\
\hline \multicolumn{8}{|c|}{ Negative dimension (12-38) } \\
\hline Intercept & & & & $16.89(0.29)$ & $<0.01$ & $18.48(1.53)$ & $<0.01$ \\
\hline No adversity & 249 & $16.9(4.3)$ & $12-38$ & Reference & & Reference & \\
\hline One early adversity & 38 & $18.5(5.1)$ & $12-33$ & $1.63(0.79)$ & 0.04 & $1.62(0.79)$ & 0.04 \\
\hline$\geqslant 2$ early adversities & 32 & $19.7(5.5)$ & $12-33$ & $2.79(0.85)$ & $<0.01$ & $2.46(0.88)$ & $<0.01$ \\
\hline Intercept & & & & $17.27(0.29)$ & $<0.01$ & $19.02(1.54)$ & $<0.01$ \\
\hline No cannabis use & 260 & $17.3(4.7)$ & $12-38$ & Reference & & Reference & \\
\hline Use mild/moderate & 30 & $17.8(4.9)$ & $12-33$ & $0.49(0.90)$ & 0.58 & $0.79(0.89)$ & 0.37 \\
\hline Heavy user & 29 & $17.8(4.3)$ & $12-28$ & $0.55(0.91)$ & 0.54 & $1.04(0.92)$ & 0.26 \\
\hline \multicolumn{8}{|c|}{ Depressive dimension (8-32) } \\
\hline Intercept & & & & $12.69(0.24)$ & $<0.01$ & $15.08(1.26)$ & $<0.01$ \\
\hline No adversity & 249 & $12.7(3.4)$ & $8-29$ & Reference & & Reference & \\
\hline One early adversity & 38 & $14.2(4.7)$ & $9-30$ & $1.51(0.66)$ & 0.02 & $1.54(0.65)$ & 0.02 \\
\hline$\geqslant 2$ early adversities & 32 & $16.5(5.1)$ & $10-32$ & $3.83(0.71)$ & $<0.01$ & $3.40(0.73)$ & $<0.01$ \\
\hline Intercept & & & & $13.18(0.25)$ & $<0.01$ & $15.81(1.30)$ & $<0.01$ \\
\hline No cannabis use & 260 & $13.2(3.9)$ & $8-32$ & Reference & & Reference & \\
\hline Use $\mathrm{mild} / \mathrm{moderate}$ & 30 & $13.4(4.8)$ & $9-30$ & $0.21(0.76)$ & 0.77 & $0.56(0.75)$ & 0.46 \\
\hline Heavy user & 29 & $13.8(3.7)$ & $9-22$ & $0.61(0.78)$ & 0.43 & $1.19(0.78)$ & 0.13 \\
\hline \multicolumn{8}{|l|}{ Total score (33-92) } \\
\hline Intercept & & & & $44.59(0.61)$ & $<0.01$ & $48.33(3.22)$ & $<0.01$ \\
\hline No adversity & 249 & $44.6(8.7)$ & $33-81$ & Reference & & Reference & \\
\hline One early adversity & 38 & 48.5 (11.2) & $34-86$ & 3.95 (1.67) & 0.02 & $3.93(1.67)$ & 0.02 \\
\hline$\geqslant 2$ early adversities & 32 & $53.9(13.4)$ & $36-92$ & $9.30(1.80)$ & $<0.01$ & $8.49(1.86)$ & $<0.01$ \\
\hline Intercept & & & & $45.62(0.62)$ & $<0.01$ & $50.25(3.31)$ & $<0.01$ \\
\hline No cannabis use & 260 & $45.6(9.7)$ & $33-92$ & Reference & & Reference & \\
\hline Use $\mathrm{mild} / \mathrm{moderate}$ & 30 & 46.8 (12.3) & $34-86$ & $1.17(1.93)$ & 0.54 & $1.89(1.91)$ & 0.32 \\
\hline Heavy user & 29 & $48.6(9.7)$ & $35-71$ & $2.96(1.96)$ & 0.13 & $4.11(1.97)$ & 0.04 \\
\hline
\end{tabular}

CAPE = Community Assessment of Psychic Experiences; SD = standard deviation; SE = standard error.

Bold font denotes statistical significance.

* Adjusted by sex, age, marital status, and years of study.

persistence, and intensity of exposure to early stress with worse mental health outcomes, which corroborates previous findings. ${ }^{35}$

The association between PE and cannabis use was significant only in the positive dimension, which was similar to the findings of studies conducted with nonclinical populations in other countries. ${ }^{36}$ This reinforces the fact that the higher the substance use, the greater the rate of PEs in the studied population. ${ }^{37}$

This study has some limitations. First, conducting a pilot study to test the semantic quality of the questions could have helped reformulate items later considered of low comprehension. Second, we were unable to test the effects of specific subtypes of abuse and neglect and their association with PEs due to the relatively scarcity of participants in the population-based group who reported each adversity subtype. In addition, the CAPE does not collect temporal data on PE onset, and thus we were unable to refine our statistical analysis by including volunteers whose PE onset was prior to the occurrence of childhood adversity or initiation of cannabis use. Regarding the inclusion of our volunteers, no randomization method was possible in sibling recruitment, which could have led to a bias towards recruiting healthier siblings. It is important to point out that the included siblings might have been the patients' caregivers, and for this reason agreed to take part in the study.

Despite these limitations, our study has a number of strengths. Firstly, the non-psychotic group, consisting of population-based participants residing in the epidemiologic 
catchment area, ensured greater representativeness of the general population. ${ }^{38}$ This approach also strengthened the search for further psychometric evidence of the CAPE instrument, as well as characterization of manifestations in the psychosis spectrum, in the general population. ${ }^{4}$ Secondly, using a standardized instrument to confirm the psychiatric diagnosis (SCID for DSM-IV) ensured the exclusion of participants with psychotic disorders from the general population. Finally, this is the first study to validate a version of the CAPE in an emerging country, which has allowed investigation of PEs in a Brazilian sample. Our study will certainly contribute to future epidemiological studies aiming to understand the psychosis spectrum in developed and emerging nations.

In conclusion, the Brazilian version of the CAPE presented acceptable psychometric properties after excluding nine items. In a population-based sample, PEs were reported by people not diagnosed with any psychotic disorder. Likewise, PEs were associated with common adversity, such as childhood adversities, and cannabis use in individuals from the community, which is similar to what has been described in other countries and cultures and reinforces the validity of the CAPE. Given that PEs are more prevalent than psychotic disorders, this phenomenon could represent an intermediate step towards a better understanding of psychoses. Further studies that seek associations between PEs and other social and biological risk factors could contribute to a deeper understanding of the etiology and physiopathogenesis of psychoses, as well as the risk and protective factors for psychoses in emerging countries. Finally, it would be interesting to compare the CAPE's psychometric performance with other instruments validated in Brazil, e.g., the Composite International Diagnostic Interview, ${ }^{39}$ the Positive and Negative Syndrome Scale, the Schizotypal Personality Questionnaire, ${ }^{40}$ and the Magical Ideation scale, ${ }^{41}$ which could be used to estimate the occurrence of PE-related constructs.

\section{Acknowledgements}

This research received financial support from the Fundação de Amparo à Pesquisa do Estado de São Paulo (FAPESP; 2012/05178-0). TCCR received a grant from CNPq (process 162125/2014-3). RS (process 2013/111673), FC-Z (process 2019/13229-2), and DLR (process 2018/07581-2) received grants from FAPESP. JS and JM are supported by Infraestrutura Nacional de Computação Distribuída (INCD), funded by Fundação para a Ciência e a Tecnologia (FCT) and Fundo Europeu de Desenvolvimento Regional (FEDER; project 22153-01/ SAICT/2016). PRM and CMD-B received productivity grants from the Conselho Nacional de Desenvolvimento Científico e Tecnológico (CNPq; 307492/2014-1 and 303815/2015-9, respectively).

\section{Disclosure}

The authors report no conflicts of interest.

\section{References}

1 Stilo SA, Murray RM. The epidemiology of schizophrenia: replacing dogma with knowledge. Dialogues Clin Neurosci. 2010;12:305-15.

2 Loch AA, Wang YP, Rössler W, Tófoli LF, Silveira CM, Andrade LH. The psychosis continuum in the general population: findings from the São Paulo Epidemiologic Catchment Area Study. Eur Arch Psychiatry Clin Neurosci. 2011;261:519-27.

3 Stefanis NC, Hanssen M, Smirnis NK, Avramopoulos DA, Evdokimidis IK, Stefanis CN, et al. Evidence that three dimensions of psychosis have a distribution in the general population. Psychol Med. 2002;32:347-58.

4 van Os J, Linscott RJ, Myin-Germeys I, Delespaul P, Krabbendam L. A systematic review and meta-analysis of the psychosis continuum: evidence for a psychosis proneness-persistence-impairment model of psychotic disorder. Psychol Med. 2009;39:179-95.

5 Linscott RJ, van Os J. An updated and conservative systematic review and meta-analysis of epidemiological evidence on psychotic experiences in children and adults: on the pathway from proneness to persistence to dimensional expression across mental disorders. Psychol Med. 2013;43:1133-49.

6 Schubart CD, van Gastel WA, Breetvelt EJ, Beetz SL, Ophoff RA, Sommer IE, et al. Cannabis use at a young age is associated with psychotic experiences. Psychol Med. 2011;41:1301-10.

7 Vinkers $\mathrm{CH}$, van Gastel WA, Schubart CD, Van Eijk KR, Luykx JJ, van Winkel $R$, et al. The effect of childhood maltreatment and cannabis use on adult psychotic symptoms is modified by the COMT Val ${ }^{1}$ Met polymorphism. Schizophr Res. 2013;150:303-11.

8 Morgan C, Fisher H, Hutchinson G, Kirkbride J, Craig TK, Morgan K, et al. Ethnicity, social disadvantage and psychotic-like experiences in a healthy population based sample. Acta Psychiatr Scand. 2009;119: 226-35.

9 van Os J, Hanssen M, Bijl RV, Ravelli A. Strauss (1969) revisited: a psychosis continuum in the general population? Schizophr Res. 2000;45:11-20.

10 Scott J, Chant D, Andrews G, McGrath J. Psychotic-like experiences in the general community: the correlates of CIDI psychosis screen items in an Australian sample. Psychol Med. 2006;36: 231-8.

11 van Os J, Hanssen M, Bijl RV, Vollebergh W. Prevalence of psychotic disorder and community level of psychotic symptoms: an urban-rural comparison. Arch Gen Psychiatry. 2001;58:663-8.

12 Brenner K, Schmitz N, Pawliuk N, Fathalli F, Joober R, Ciampi A, et al. Validation of the English and French versions of the Community Assessment of Psychic Experiences (CAPE) with a Montreal community sample. Schizophr Res. 2007;95:86-95.

13 Daneluzzo E, Di Tommaso S, Tempesta D, Cerroni G, Stratta P, Rossi A. [The Community Assessment Psychic Experience (CAPE): evaluation study of the Italian version]. Epidemiol Psichiatr Soc. 2008;17:242-7.

14 Fonseca-Pedrero E, Paino M, Lemos-Giraldez S, Muniz J. Validation of the Community Assessment Psychic Experiences-42 (CAPE-42) in Spanish college students and patients with psychosis. Actas Esp Psiquiatr. 2012;40:169-76.

15 Schlier B, Jaya ES, Moritz S, Lincoln TM. The Community Assessment of Psychic Experiences measures nine clusters of psychosislike experiences: a validation of the German version of the CAPE. Schizophr Res. 2015;169:274-9.

16 Mark W, Toulopoulou T. Psychometric properties of "Community Assessment of Psychic Experiences": review and meta-analyses. Schizophr Bull. 2016;42:34-44.

17 Del-Ben CM, Shuhama R, Loureiro CM, Ragazzi TC, Zanatta DP, Tenana $\mathrm{SH}$, et al. Urbanicity and risk of first-episode psychosis: incidence study in Brazil. Br J Psychiatry. 2019;215:726-9.

18 Jongsma HE, Gayer-Anderson C, Lasalvia A, Quattrone D, Mulè A, Szöke A, et al. Treated incidence of psychotic disorders in the Multinational EU-GEI Study. JAMA Psychiatry. 2018;75:36-46.

19 Instituto Brasileiro de Geografia e Estatística (IBGE). Tabela 1378: População residente, por situação do domicílio, sexo e idade, segundo a condição no domicílio e compartilhamento da responsabilidade pelo domicílio [Internet]. [cited 2020 Jan 13]. https://sidra. ibge.gov.br/tabela/1378\#resultado

20 Guloksuz S, Pries LK, Delespaul P, Kenis G, Luykx JJ, Lin BD, et al. Examining the independent and joint effects of molecular genetic 
liability and environmental exposures in schizophrenia: results from the EUGEI study. World Psychiatry. 2019;18:173-82.

21 Del-Ben CM, Vilelab JAA, Crippab JA de S, Hallaka JEC, Labatec $\mathrm{CM}$, Zuardi AW. Confiabilidade da entrevista clínica estruturada para o DSM-IV: versão clínica traduzida para o português. Braz J Psychiatry. 2001;23:156-9.

22 Pignon B, Peyre H, Ferchiou A, van Os J, Rutten BP, Murray RM, et al. Assessing cross-national invariance of the Community Assessment of Psychic Experiences (CAPE). Psychol Med. 2019;49:2600-7.

23 Bernstein DP, Stein JA, Newcomb MD, Walker E, Pogge D, Ahluvalia $\mathrm{T}$, et al. Development and validation of a brief screening version of the Childhood Trauma Questionnaire. Child Abuse Negl. 2003;27: 169-90.

24 Grassi-Oliveira R, Stein LM, Pezzi JC. [Translation and content validation of the Childhood Trauma Questionnaire into Portuguese language]. Rev Saude Publica. 2006;40:249-55.

25 Di Forti M, Morgan C, Dazzan P, Pariante C, Mondelli V, Marques $\mathrm{TR}$, et al. High-potency cannabis and the risk of psychosis. $\mathrm{Br} \mathrm{J}$ Psychiatry. 2009;195:488-91.

26 Marôco J. Análise de equações estruturais: fundamentos teóricos, software e aplicações. $2^{\mathrm{a}}$ ed. Pêro Pinheiro: ReportNumber; 2014.

27 Byrne BM. Structural equation modeling with AMOS: basic concepts, applications, and programming. 3rd ed. New York: Routledge; 2010.

28 Instituto Nacional de Estudos e Pesquisas Educacionais Anísio Teixeira. Índice de desenvolvimento da educação básica: resultados e metas [Internet]. [cited 2020 Jan 13]. http://ideb.inep.gov.br/resultado/resultado/resultadoBrasil.seam?cid $=9479504$

29 Gmitroski T, Bradley C, Heinemann L, Liu G, Blanchard P, Beck C, et al. Barriers and facilitators to employment for young adults with mental illness: a scoping review. BMJ Open. 2018;8:e024487.

30 Murray CJ, Vos T, Lozano R, Naghavi M, Flaxman AD, Michaud C, et al. Disability-adjusted life years (DALYs) for 291 diseases and injuries in 21 regions, 1990-2010: a systematic analysis for the Global Burden of Disease Study 2010. Lancet. 2012;380:2197-223.

31 Linscott RJ, van Os J. Systematic reviews of categorical versus continuum models in psychosis: evidence for discontinuous subpopulations underlying a psychometric continuum. Implications for DSM-V, DSM-VI, and DSM-VII. Annu Rev Clin Psychol. 2010;6:391-419.
32 McGrath JJ, Saha S, Al-Hamzawi A, Alonso J, Bromet EJ, Bruffaerts $\mathrm{R}$, et al. Psychotic experiences in the general population: a cross-national analysis based on 31261 respondents from 18 countries. JAMA Psychiatry. 2015;72:697-705.

33 Trotta A, Murray RM, David AS, Kolliakou A, O'Connor J, Forti M Di, et al. Impact of different childhood adversities on 1-year outcomes of psychotic disorder in the genetics and psychosis study. Schizophr Bull. 2016;42:464-75.

34 Varese F, Smeets F, Drukker M, Lieverse R, Lataster T, Viechtbauer $\mathrm{W}$, et al. Childhood adversities increase the risk of psychosis: a metaanalysis of patient-control, prospective- and cross-sectional cohort studies. Schizophr Bull. 2012;38:661-71.

35 Wigman JT, van Winkel R, Jacobs N, Wichers M, Derom C, Thiery $E$, et al. A twin study of genetic and environmental determinants of abnormal persistence of psychotic experiences in young adulthood. Am J Med Genet B Neuropsychiatr Genet. 2011;156B: 546-52.

36 Vreeker A, Schubart CD, van Gastel WA, Kahn RS, Boks MP. Advanced paternal age and vulnerability to psychotic-like experiences in the offspring. Schizophr Res. 2013;143:74-6.

37 van Gastel WA, Vreeker A, Schubart CD, MacCabe JH, Kahn RS, Boks MP. Change in cannabis use in the general population: a longitudinal study on the impact on psychotic experiences. Schizophr Res. 2014;157:266-70.

38 Matijasevich A, Menezes PR. Princípios de epidemiologia. In: Martins MA, Carrilho FJ, Alves VAF, Castilho EA, Cerri GG, Duarte AJS, et al. editors. Clínica médica. Barueri: Manole; 2009. p. 371-80.

39 Quintana MI, Andreoli SB, Jorge MR, Gastal FL, Miranda CT. The reliability of the Brazilian version of the Composite International Diagnostic Interview (CIDI 2.1). Braz J Med Biol Res. 2004;37: 1739-45.

40 Tonelli $H$, von der Heyde MD, Alvarez CE, Raine A. Versão em português do Questionário da Personalidade Esquizotípica - SPQ. Rev Psiquiatr Clin. 2009;36:34-7.

41 Vieira PG, Villemor-Amaral AE de, Pianowski G. Tradução, adaptação e evidências iniciais de validade da Magical Ideation Scale TT - Translation, Adaptation and Initial Validity Study of the Magical Ideation Scale. Psicol Teor Pesq. 2016;32:e324222. 